\title{
TRUYỆN CỔ TÂY NGUYÊN VÀ TRUYÊN CỔ ĐÔNG NAM Á MộT SỐ MOTIF CHUNG
}

\author{
Lê Hồng Phong ${ }^{a^{*}}$
}

${ }^{a}$ Trường Đại học Đà Lạt, Lâm Đồng, Việt Nam

Nhận ngày 10 tháng 11 năm 2015

Chỉnh sửa ngày 07 tháng 02 năm 2016 | Chấp nhận đăng ngày 20 tháng 02 năm 2016

\section{Tóm tắt}

Truyện cổ Tây Nguyên có nhũng tuơng đồng và khác biệt với khu vực Đông Nam Á về thể loại, nhân vật, nội dung văn học và giá trị văn hóa. Bài viết giới thiệu nhũng tuoong đồng và một vài khác biệt của các thể loại truyện cổ Tây Nguyên trong tuơng quan khu vực về phuơng diện motif.

Từ khóa: Đông Nam Á; Motif; Truyện cổ; Tây Nguyên; Tương đồng.

Tây Nguyên là địa bàn chiến lược của Việt Nam, Tây Nguyên cũng là vùng văn hóa mang bản sắc độc đáo với nhà rông, tượng gỗ, rượu cần, sử thi, truyện cổ... Truyện cổ Tây Nguyên có những tương đồng và khác biệt với khu vực Đông Nam Á về thể loại, nhân vật, nội dung văn học và giá trị văn hóa. Bài viết tập trung giới thiệu những tương đồng của các thể loại truyện cổ Tây Nguyên trong tương quan khu vực về phương diện motif. Thỉnh thoảng có đề cập tới một số nét riêng, một vài khác biệt nhưng trọng tâm của tiểu luận vẫn là những điểm tương đồng của truyện cổ Tây Nguyên trong tương quan khu vực.

\section{HUYỀn THOẠI TÂY NGUYÊN VÀ NHŨNG MOTIF CHUNG ĐÔNG NAM Á}

Trong huyền thoại Đông Nam Á rất phổ biến motif cây. Huyền thoại Mường có motif cây si sinh thành nhiều thứ, trong đó có motif cây sinh chim, chim sinh bầu.

\footnotetext{
*Tác giả liên hệ: Email: phonglh@dlu.edu.vn
} 
Người Việt có bọc trăm trứng trăm con, người Mường có bầu trăm trứng; cả hai dân tộc đều có motif người miền xuôi, người miền núi đều là an hem cùng một mẹ. Huyền thoại Mường có 3 trứng nở ra Lang Đá Cần, Lang Đá Cài và nàng Vạ Hai Kịp. Tiếp đó là motif hôn nhân đồng huyết: Lang Đá Cài lấy Vạ Hai Kịp; motif cây: Dịt Dàng tìm cây Chu, chặt cây.

Cùng motif cây lại có những tiểu motf - motif nhỏ. Huyền thoại Lào, Ê Đê, Chăm, K'Ho... đều xuất hiện motif chặt cây thần - cây che mặt trời, che sự sống cộng đồng. Chặt cây, máu cây sinh thú, cây có máu như người, người như cây, người như thú, máu cây hóa thú hay cây sinh thú, cây sinh người. Biểu hiện của motif cây cũng rất phong phú: cây thuốc đá Keo reng của người Mường, cây thuốc tiên của Cuội (Việt Mường), cây hồi sinh, gậy hồi sinh (Sơn Tinh), cây lúa có hạt lớn tự về nhà (ÊE Đê, Việt...), cây sống lại, cây sinh người (Mạ, K’Ho), cây bản mệnh của người (cây smuk Ê Đê), cây vận mệnh dân tộc (cây krêt - Chăm), cây lúa từ phân chim (K'Ho), từ hạt bám kẽ chân mà người lấy được lúa thần (Indonexia), cây tre hoặc măng sinh ra người (Malaixia, Philippin) v.v...

Ở Tây Nguyên cao $2000 \mathrm{~m}$ cũng có huyền thoại lụt với sự phổ biến của motif lụt và motif bầu, có motif quả bầu- thuyền, quả bầu - con và rất hiếm quả bầu - mẹ. Trong 307 dị bản do Đặng Nghiêm Vạn sưu tầm và công bố, các dân tộc Tây Nguyên rất ít motif quả bầu- me so với type (kiểu) truyện quả bầu Lào mà Nguyễn Tất Đắc đã khái quát. Ở truyện cổ Lào, Trời làm lụt, ba ông Khún đóng thuyền lên trời tránh lụt, trời cho trâu, trâu chết, mọc dây bầu một quả (motif quả bầu mẹ, motif cái duy nhất), chọc thủng bầu, các bộ tộc Lào chui ra, chặt cây đa, giết đại bàng cứu sự sống cộng đồng. Theo huyền thoại Mạ, K’Ho (Nam Tây Nguyên) thì sau nạn lụt, cũng tương tự nhiều huyền thoại khác ở Đông Nam Á, anh/chị em - cặp duy nhất sống sót phải lấy nhau theo ý thần linh, nhưng không sinh ra bầu con như huyền thoại Đông Nam Á, mà cơ bản sinh ra ba dân tộc: Kon Prum (Chăm), Kon Chau (người Thượng) và Kon Yoan (Việt)... Tính chất chung của huyền thoại Lào và huyền thoại Tây Nguyên trước hết là ở lớp văn hóa muộn của nó: người Thượng phải tiếp xúc với Chăm, Việt thì mới bổ sung thêm lớp văn hóa mới vào huyền thoại của mình; sự thống nhất ba bộ tộc Lào Thưng, Lào Lùm, 
Lào Xủng trong một nước Lạn Xạng đã được biểu hiện vào trong huyền thoại tộc người của Lào... Do vậy, huyền thoại Đông Nam Á dù cổ xưa, cũng không hoàn toàn quá xa thời đại chúng ta sống.

Với huyền thoại Philippin, Sicalak và Sicabai là cặp đầu tiên được sinh ra từ măng tre, vẫn là motif cây sinh người trong tổng thể motif cây. Giã gạo, trời xa đất, lược thành trăng, lò lửa thành mặt trời. Ở huyền thoại Nam Tây Nguyên: bầu trời được làm từ lưng trâu, mặt trăng từ sừng trâu...; mặt trời, mặt trăng đều được rèn từ lò lửa của N’Đu. Mặt trời, lò lửa có nét gần nhau về màu đỏ, sức nóng, khả năng đốt cháy; tục giữ lửa, thờ lửa cũng gắn với thờ mặt trời, cả hai đều cần cho sự sống. Người có phép kêu mưa, gọi gió, giữ gươm thiêng, được tôn xưng và tin tưởng như một thủ lĩnh tín ngưỡng (Pơtao Ea, Pơtao Pui) mà chúng ta quen dịch thoát là vua Nước, vua Lửa!

Mặt trời trong huyền thoại Philippin buồn, đòi lấy vợ, con gái thủ lĩnh tự nguyện lấy thân để ánh sáng mạnh lên cho cộng đồng sinh sống. Người Tây Nguyên cũng quan niệm về mặt trời với tính chất nhân hóa như vậy. Đó là một thế giới khác vừa như người vừa hùng mạnh hơn người, thế giới mặt trời gồm nhiều “người - mặt trời” có già, trẻ, gái, trai, có thủ lĩnh là mơtao, pơtao Mặt trời. Mô hình tổ chức cộng đồng người chi phối cách hình dung về thế giới thần, quan hệ thần - người, thần - ma, thần và ma với người...

Có núi lửa ở Philippin là do người vi phạm điều cấm (tự tiện lên núi, dám nhìn núi vàng, núi bạc). Người R'măm Tây Nguyên cho rằng đất sụp (núi lửa tiền sử Tây Nguyên) là do con người ăn thịt heo thiêng! Người Mạ và K'Ho cho rằng người ta có thể đuổi ma ra khỏi nguoờ - ma, để người - ma thành người thường, trong khi đó, ai ăn con heo - ma sẽ thành người - ma.

Huyền thoại Miến có nhiều mặt trời thiêu hủy thế giới; biển dâng tận trời (motif lụt). Ba anh em: Sun - Mặt trời - Mặt trăng ghét nhau, Sun đuổi theo hai anh đòi lại thuốc bất tử, che lấp nhau thành nhật thực, nguyệt thực... Người Nam Tây Nguyên quan niệm mặt trăng, mặt trời tìm nhau, che lấp nhau... thành nhật thực, nguyệt thực. 
Người Miến quan niệm có bốn vị thần đầu tiên xuống trần, nặn bốn cặp đầu tiên bằng đất, hong thần lửa, thành bốn chủng trắng, đỏ, tối, đen. Người Tây Nguyên cũng được nặn ra bằng đất màu, sống trong hang, rồi chui lên trên... (Ê Đê, M’Nông, K’Ho, Mạ...). Loài người thứ nhất chết trong hồng thủy, các tộc người hiện nay là loài người thứ hai. Tổ tiên người Miến đến từ cõi trời Dan với các bama bất tử, Tây Nguyên theo tín ngưỡng đa thần (Yang, Yàng). Dan - Yan - Yang, Yàng là các từ cùng gốc? Giả thiết này phải nhờ cậy các nhà ngôn ngữ học lịch sử.

Motif thỏ cung trăng có trong huyền thoại San và Miến của Mianma: thỏ bạc ngồi nhà thủy tinh 15 cửa, mỗi đêm mở 1 cửa, 15 ngày mở 15 cửa, tiếp tục đóng lần lượt mỗi đêm thêm 1 cửa thì được 1 tháng. Ở huyền thoại Trung Quốc có Hậu Nghệ, Hằng Nga, có thỏ ngọc và cây trường sinh trên cung trăng; huyền thoại Mường có cây đa và chú Cuội. Thỏ có rất nhiều trong truyện cổ Tây Nguyên nhưng tính chất ngụ ý pha lẫn tính chất hài.

Người Indonexia quan niệm trời đất ban đầu là một khối do ánh sáng, bọt biển, hơi nước (văn hóa biển), nhưng là nhất thể, hỗn độn như huyền thoại Hy Lạp, Việt, Mường... Trời sinh nhiều con, con của trời khóc nhớ thành sương, con của trời tức giận thành bão... Người Mạ, K’Ho cho rằng tổ tiên - thần linh ban đầu hóa thân sáng tạo: Kblop thành cá, $\mathrm{KB}$ 'la thành muối, $\mathrm{K}$ 'los thành sắt...

\section{CỖ TÍCH TÂY NGUYÊN VÀ NHỬNG MOTIF CHUNG ĐÔNG NAM Á}

Các motif cổ trong huyền thoại vẫn được duy trì theo những cách khác nhau trong cổ tích. Đó là motif cây trong đó có phổ biến là các motif cây si, đa, bầu; motif chim, motif thần xuất hiện để thử thách, giúp đỡ con người; có các motif mới như mồ côi, mang lốt, biến hóa, kết hôn, motif dũng sĩ diệt ác thú cưu ngườ đẹp qua type truyện Thạch Sanh, motif con chung con riêng qua type truyện Tấm Cám rất phổ biến ở Đông Nam Á.

Kiểu (type) truyện Thạch Sanh thuộc loại phổ biến nhất ở Đông Nam Á, đã được Nguyễn Bích Hà nghiên cứu thành công trình riêng, có kế tục Hoa Bằng, Cao Huy Đỉnh, Hoàng Tiến Tựu... Kiểu truyện này có nhiều motif chung: motif dũng sĩ, motif 
cây đa, tín ngưỡng và tục tế thần tự nhiên bằng người sống; motif diệt ác thần (chằn tinh, đại bàng, mãng xà) cứu người; motif cô gái câm; motif tiếng đàn (tiếng hát) đuổi thú, đuổi thù cứu cộng đồng; motif kết hôn, lên ngôi... Người Việt có thêm niêu cơm thần - khát vọng no đủ của cư dân lúa nước, trong motif sự tha thứ chung của Đông Nam Á, người Việt để Thạch Sanh tha thứ cho mẹ con Lý Thông, nhưng trên đường về bị sét đánh, hóa thân làm bọ hung.

Kiểu truyện mồ côi với quan hệ chị em khác mẹ cũng phổ biến ở Đông Nam Á. Ở Việt Nam, người Việt và các dân tộc phía Bắc khá gần nhau ở việc khắc họa mâu thuẫn chị em cùng cha và mâu thuẫn dì ghẻ - con chồng; người Chăm lại thể hiện mâu thuẫn con đẻ - con nuôi; người Mạ cũng có motif chị em con cô-con cậu, chưa đặt ra vấn đề dì ghẻ đúng như trình độ phát triển của một xã hội cuối mẫu hệ (Ít và Dong).

Cùng type truyện nhưng các dân tộc ở Đông Nam Á cũng có những điểm khác biệt nhất định: mẹ Chăn Tha (Lào) hóa thân thành rùa vàng, thành bồ đề - biểu tượng Phật giáo; Tấm (Việt - Việt Nam) biến hóa nhiều kiếp, có Phật xuất hiện nhưng với danh xưng Bụt đậm nét dân gian; truyện cổ Mạ thì nhân vật không hóa thành xoan, thị mà thành chim, trúc, măng, dưa leo, quýt... Không gian cư trú và canh tác, tín ngưỡng về tự nhiên và mối quan hệ với tự nhiên chi phối chi tiết cây trong motif cây và nhiều motif khác.

Sự tha thứ là motif chung của cổ tích Tây Nguyên cũng như hầu hết cổ tích Đông Nam Á; trong khi đó, Tấm của người Việt lại trừng phạt em và dì ghẻ, nhưng không phải là vấn đề bàn ở đây. Xét về các motif chung, các nội dung tín ngưỡng, phong tục, quan hệ thiện - ác trong truyện, cả sự kết thúc truyện, lại thấy rằng truyện cổ Tây Nguyên, cổ tích Chăm gần gũi Đông Nam Á hơn.

Sự phổ biến của nhân vật mồ côi trong cổ tích giúp chúng ta xem xét lại một số quan điểm chung về sự ra đời và phát triển của thể loại cổ tích, về nội dung đấu tranh giai cấp của truyện mồ côi nói riêng, cổ tích nói chung. Yếu tố thần kỳ cũng rất đậm đặc trong cổ tích nhiều nước cho nên không thể lấy thần kỳ làm tiêu chí phân loại cổ tích được. Các tín ngưỡng nguyên thủy bản địa, các phong tục, các lễ hội, các lĩnh vực văn 
hóa vật chất và tinh thần được phản ánh trong cổ tích làm cho cổ tích Đông Nam Á hàm chứa những giá trị văn hóa rất phong phú.

\section{TRUYỆN HÀI - NGỤ NGÔN TÂY NGUYÊN SO VỚI ĐÔNG NAM Á}

Ở Tây Nguyên rất phổ biến type truyện mà các nhân vật là động vật như thỏ, rùa, khỉ, cọp, voi... mà người kể chuyện gọi trân trọng là ông thỏ (pàng pài), ông cọp (pàng klìu)... Về cơ bản, truyện không chú trọng đến đời sống hay tập tính loài vật, mà thông qua các động vật và quan hệ vật - vật để ngụ ý một vài đặc điểm của con người và quan hệ người - người theo hướng ngụ ngôn.

So sánh với truyện cổ Đông Nam Á thì chất ngụ ngôn ở đây chưa cao, chưa súc tích, chưa cô động. Dung lượng truyện rất lớn, hành động nhân vật lặp đi lặp lại theo các motif bắt chước, motif mẹo lìa, motif khôn - dại. Đồng thời yếu tố ngụ ngôn đang gắn kết với yếu tố hài. Chúng tôi cho rằng, với Tây Nguyên, truyện hài và truyện ngụ ngôn chưa phát triển thành hai thể loại độc lập mà đang trong quá trình vận động, đang ở giai đoạn tiền thể loại: tiền - truyện hài và tiền - ngụ ngôn. Trong khi đó, truyện ngụ ngôn ở một số dân tộc Đông Nam Á đã phát triển với tư cách một thể loại ngắn, tính ngụ ý cao, tính chất hài vẫn còn nhưng dù sao cũng đã có một thể loại truyện cười riêng.

Trong truyện cổ Thái Lan, có truyện về loài chim mà kết cấu tương tự truyện về thỏ và truyện về rùa của Tây Nguyên. Độ kết dính giữa các tiểu truyện cũng còn khá lỏng lẽo mà khi thay đổi trật tự một số kiểu truyện, giá trị toàn hệ thống cơ bản được giữ nguyên. Tuy nhiên, từng tiểu truyện về loài chim có thể được kể độc lập với tính chất ngụ ngôn của nó; còn từng tiểu truyện về rùa hay về thỏ ở Tây Nguyên thì tính chất hài trội hơn bài học ngụ ngôn.

Với người Việt (Việt Nam), người Khmer (Việt Nam và Campuchia) và người Lào (Việt Nam và Lào) đều có chung một tiểu loại truyện trạng (Trạng Quỳnh, Xiêng Miệng, Thơ Miêng Chây...). Truyện trạng Đông Nam Á có sự tương đồng về kết cấu hệ thống, tính chất liên hoàn, xâu chuỗi thông qua nhân vật chính; có một số motif chung mà chưa biết nước nào mượn của nước nào: Thuốc ngon cơm, Gà trống không biết đẻ, Nhò̀ phân cung nư... trong Xiêng Miệng rất gần gũi với Món ăn mầm đá, Sao sáng xú 
Thanh, Rau cải tiến chúa trong Trạng Quỳnh; cả Lào và Campuchia đều chung các motif: Tôi không dám nhặt; Tôi nhặt tất cả...Trong truyện trạng của cả ba dân tộc chủ thể của ba quốc gia này đều có những chuyện lỡm sứ Tàu, vua Tàu... Tuy nhiên, về phương diện nào đó, truyện về thỏ hay truyện về rùa của Tây Nguyên vẫn có nét chung về tính chất đồ sộ, kết cấu lỏng lẻo, về tính chất liên hoàn, tính chất hài như truyện trạng (Trạng Quỳnh, Xiêng Miệng, Tho Mênh Chây, Cuội...) ở Đông Nam Á. Chúng ta cần tiếp tục nghiên cứu thêm để sáng tỏ tiến trình phát triển của các thể loại truyện cổ Đông Nam Á.

\section{NGUYÊN NHÂN CỦA SỰ TƯƠNG ĐỒNG}

\subsection{Sự tương đồng do cùng gốc tộc người hoặc cùng vùng cư trú cổ.}

Tuyển tập thần thoại Đông Nam Á mà chúng tôi đang khảo sát coi Đẻ đất đẻ nước là huyền thoại Việt - Mường...là theo quan điểm Việt và Mường cùng gốc. Một bộ phận người Nguồn từ Quảng Bình vào cư trú ở Lâm Đồng, năm 1999, đoàn sưu tầm của chúng tôi đã ghi được hàng trăm đơn vị hát Đúm của họ về tình yêu mà không cần phiên dịch, bởi cư dân này nói bằng thứ tiếng Việt - Mường cổ, gần phương ngữ Nghệ Tĩnh ngày nay. Phải chăng, trong quá khứ, Nguồn cũng từ Việt - Mường mà ra? Các bộ phận Thái bao gồm Thái (Trung Quốc), Thái (Việt Nam), Thái (Thái Lan)... có lẽ cũng vậy.

\subsection{Sự tương đồng do các dân tộc di cư, xen cư, giao lưu văn hóa.}

Trong kho tàng truyện cổ Lào đã tồn tại các truyện: Nàng Xip xoỏng (Nàng Mười hai), Khăm pha (Mồ côi), Khăm pha - nàng Ngà (Mồ côi và nàng Ngà), Bò mi pho (Không có cha)v.v... Những truyện này được sưu tầm, in ấn, xuất bản ở Lào và đã dịch và xuất bản ở Việt Nam. Tháng $1 / 2000$, Đoàn sưu tầm văn học dân gian tại Bản Đôn cũng thâu lượm được dị bản của các truyện này tại vùng cư trú của người Lào (và các cư dân nói tiếng Lào) có quốc tịch Việt Nam. Tính chất giao lưu văn hóa trong cộng đồng dân tộc ở Bản Đôn là có thật, nhưng trước đó, sự chuyển cư của người Lào từ Lào qua Việt Nam đã khiến cho trong tổng thể truyện cổ Tây Nguyên hay truyện cổ Việt 
Nam có bộ phận truyện cổ Lào với những nét tương đồng nhất định với truyện cổ Lào tại Lào, và có thể cả một số nước khác trong vùng Đông Nam Á.

\subsection{Sự tương đồng do các dân tộc và truyện cổ của họ cùng chịu ảnh hưởng một nguồn văn hóa chung.}

Hầu hết các quốc gia Đông Nam Á chịu ảnh hưởng của văn hóa Ân và các tôn giáo Ấn. Chính thế mà truyện cổ Thái Lan lại xuất hiện nhiều nhân vật tu sĩ, đạo sĩ theo cả hai hướng thiện và ác. Trong đó có nhân vật Cò thông thái Ân Độ, cu gáy Ấn Độ, thần điểu Garuda diệt rắn Naga... Truyện cổ Chăm và văn hóa chăm có Po Naga - Mẹ xứ sở, Ôn Gru (một chức sắc tôn giáo)... Tây Nguyên có Nak Grài - thần rắn sáng tạo ra sông, suối; Po Grù (thầy tu, thầy giáo, người săn được 30 con voi trở lên...)... Ấn Độ có tuyển tập ngụ ngôn Panchatantra nổi tiếng, và các dân tộc Đông Nam Á cũng vay mượn theo mức độ khác nhau để có Munlatantai, Nangtantai (Lào), Tantri (Inđônêxia), Nangtantai (Thái Lan)...

Như vậy, tôn giáo Ấn và văn hóa Ấn có thể sang các nước ở Đông Nam Á trực tiếp, trong khi cũng tôn giáo ấy và văn hóa ấy lại lên Tây Nguyên của Việt Nam gián tiếp qua con đường văn hóa Chăm, Lào... Xét bề mặt, văn hóa một dân tộc có thể đến một dân tộc khác bằng con đường tôn giáo; nhưng suy cho cùng là văn hóa một dân tộc có thể đến một dân tộc khác qua văn hóa nếu nghĩ rằng khởi thủy mọi tôn giáo đều ra đời trên cơ sở văn hóa nguyên thủy, và tôn giáo cũng là một trong những lĩnh vực văn hóa đặc thù trong tổng thể văn hóa. Nhiều cư dân Tây Nguyên theo Tin lành và Công giáo khiến cho huyền thoại ít nhiều có xáo trộn bởi một số chi tiết ngoại lai, thì ông Phật lại có mặt trong truyện cổ Lào Bản Đôn (Việt Nam), và Phật cũng được dân gian hóa thành Bụt trong cổ tích người Việt...

\subsection{Sự giống nhau ngẫu nhiên giữa các dân tộc cùng trình độ.}

Cùng kéo dài một cách bất thường tư duy nguyên thủy, tín ngưỡng nguyên thủy; tổ chức xã hội nguyên thủy mạt kỳ, cùng phải đặt ra những câu hỏi, những vấn đề cần giải quyết tương tự như nhau cũng có thể làm xuất hiện những nét tương đồng ngẫu nhiên trong truyện cổ, trong văn hóa các dân tộc cho dù không cùng nguồn gốc, không 
giao lưu. Nói ngẫu nhiên vì chưa giao lưu, không chung nguồn gốc, không chịu ảnh hưởng cùng một nguồn chung, nhưng xét trong tiến trình phát triển con người, phát triển văn hóa nhân loại thì những vấn đề chung cần giải quyết như nhau trong thời điểm lịch sử khác nhau của từng dân tộc lại là tất nhiên, là mang tính quy luật.

\section{KẾT LUẬN}

5.1. Sự tương đồng trong khu vực văn hóa Đông Nam Á là có thật, cơ tầng văn hóa chung dẫu có chịu tác động bởi các nền văn minh lớn, nhưng vẫn có cái nền gốc chắp thêm cành lá mới. Những giá trị truyền thống là không thể phủ nhận, cần phát huy; nhưng cũng có những nhược điểm cần khắc phục của khu vực: Văn học viết chưa đột phá để vượt lên hiện đại hóa; dựa vào nền tảng văn hóa dân gian để phát triển là đúng nhưng không được nệ cổ; tích cũ của dân tộc, của khu vực, của văn hóa Ấn chi phối văn học nghệ thuật truyền thống, chi phối lối kết mang tính công thức chưa làm thỏa mãn thị hiếu công chúng hiện đại.

5.2. Từ tảng nền văn hóa chung, các dân tộc Đông Nam Á có triển vọng hội nhập, cùng phát triển, kể cả giao lưu nghiên cứu và phát triển nghiên cứu trong sự phát triển toàn diện và thịnh vượng chung của khu vực văn hóa.

5.3. Các dân tộc còn có nhiều cái độc đáo làm nên bản sắc từng dân tộc để không làm hòa tan, để vừa nhận, vừa cho, tạo sự hài hòa khu vực và nhân loại. Do phải đi tìm cái chung mang tính khu vực, nên bài viết tạm gác lại cái riêng để tìm hiểu nét tương đồng là chính. Cần tiếp tục so sánh văn hóa, văn học hai dân tộc hoặc hai quốc gia trong Đông Nam Á để khẳng định cái chung và cái độc đáo của từng dân tộc, từng quốc gia Đông Nam Á.

\section{TÀI LIỆU THAM KHẢO}

[1] Viện Đông Nam Á (1983), Văn học các nước Đông Nam Á, Viện Đông Nam Á xuất bản, Hà Nội.

[2] Chu Xuân Diên (1994), Về phương pháp so sánh trong nghiên cứu văn hóa dân gian, Tập san Khoa học, ĐHTH TpHCM, số 1/1994, tr. 44 - 55.

[3] Ngô Văn Doanh và... tuyển soạn (1990), Truyện cổ Thái Lan, Nxb. Trẻ, Tp.HCM. 
[4]. Phạm Đức Dương (1998), Giải mã truyện cổ Lào theo phương pháp tiếp cận văn hóa học, Tạp chí Văn học, Hà Nội, số 1, tr 51 - 58.

[5] Nguyễn Tấn Đắc (1995), Về các nền văn học dân tộc ở Đông Nam Á, Tạp chí Văn học, Hà Nội, số 8, tr. 2 - 4.

[6] Bích Hà (1998), Thạch Sanh và kiểu truyện dũng sĩ trong cổ tích Việt Nam và Đông Nam Á, Nxb. Giáo dục, Hà Nội.

[7] Trương Sĩ Hùng biên soạn (1988), Thần thoại Đông Nam Á, Hội Văn nghệ Quảng Nam - Đà Nẵng.

[8] Trương Sĩ Hùng biên soạn (1987), Truyện trạng Đông Nam Á, Sở VHTT Gia Lai Kon Tum.

[9] Lê Hồng Phong (2006), Tìm hiểu truyện cổ Tây Nguyên trường hợp Mạ và K'Ho, TT nghiên cứu Quốc học - Nxb. Văn học, Hà Nội.

[10] Tuyết Phượng và ... biên soạn, dịch (1981), Hợp tuyển văn học Lào, Nxb.Văn học, Hà Nội.

[11] Huỳnh Ngọc Trảng... dịch (1987), Panchatantra, Nxb Trẻ, Tp.Hồ Chí Minh.

[12] Lưu Đức Trung và...(1989), Văn học Ấn Độ, Lào, Campuchia, Nxb. Gíao dục, Hà Nội.

[13] Đặng Nghiêm Vạn (1997), Huyền thoại về nạn hồng thủy và nguồn gốc tộc người, Nghiên cứu văn hóa dân gian Việt Nam, T1, Nxb Văn hóa Dân tộc, Hà Nội, tr. 803 -863 . 


\title{
CENTRAL HIGHLANDS' TALES AND SOUTHEAST ASIAN TALES - SEVERAL COMMON MOTIFS
}

\author{
Le Hong Phong ${ }^{a^{*}}$
}

${ }^{a}$ Dalat University, Lamdong, Vietnam

*Corresponding author: phonglh@dlu.edu.vn

Article history

Received: November $10^{\text {th }}, 2015$

Received in revised form: February $07^{\text {th }}, 2016$

Accepted: February $20^{\text {th }}, 2016$

\begin{abstract}
Central Highlands' tales and Southeast Asian tales are similar and dissimilar in terms of genres, characters, content, and literature and cultural values. This article presents several similarities and a few dissimilar between the tales of the Central Highlands and those in the region of ASEAN in terms of motifs.
\end{abstract}

Keywords: Folklore; Motif; Southeast Asia; Similarity; The Central Highlands. 